\title{
Design as Semiosis: A design Mechanism for Place Branding Eirini Krasaki
}

PHD Candidate at National Technical University of Athens

eirini.krasaki@googlemail.com

\begin{abstract}
The described design methodology combines parametric design, data analysis, algorithmic design and semiotics theory to systematically analyze urban reality. The analysis leads to a creation of a nebula of data which corresponds to the place of interest. The nebula of data consists of networks of semiotics spatially defined. Through the proposed methodology, semiotics are used to enhance the perception that we have for a place and create a strategy for its' branding.

Space is not approached as an empty container but as a complex system that consists of material and immaterial elements. The characteristics of these elements are quantified by their context and the logics of description to which they correspond. Logics of description are constantly changing following the multiplicity and the expansion of concepts. Therefore, space is constantly redefined following the transformation of the corresponding virtual data.

Considering that each framework draws up an ideology following the change of context and the logics of description, a tool (machine) for analyzing written speech is developed, combining data visualization techniques, linguistics and design methodologies to configure logics of description. Written speech is transformed into a series of networks, visualizing their ontological relationships and disregarding the factor of time. A nebula of data corresponding to the mental reality of space is formed. Following a methodological procedure, the nebula of space is transformed to a nebula of place. The nebula of place contains its' key characteristics parametrized. A selection of these characteristics is combined to create the brand of the place concerning its' context and logics of description. The before mentioned methodological tool connects people, spaces, and machines enabling the connection of spatial data to create the impression (brand) of a place.
\end{abstract}

Keywords: Digital technique; Spaces; Machines 